\title{
A Conceptual and Technical Discussion on Digital Painting as New Media Art: Introducing Some Malaysian Works
}

\author{
Mumtaz Mokhtar \\ Faculty of Art and Design, University Technology MARA, \\ 40450 Shah Alam, Selangor Darul Ehsan, Malaysia \\ Email: mumtazmikaeil@gmail.com
}

\begin{abstract}
The revolution of media technology offers artists a lot of possibilities to create different art forms. The artist explored and manipulated different media to give different impact in their works since modernism and post modernism period. Malaysia as one of Asian country also committed to art development where artist explore various media in painting including conventional and technological media as well. Digital technology and art movement were developed in two separate segments. In fact, new media art does not establish in art history plot. Therefore, the word digital painting poses an ambiguity to describe its status. The convergence of scientific term and art term called digital painting will be discussed into two sections under conceptual issues and technical issues. In conceptual issues, digital painting will be linked to the ingredient and components of art including the artist, the form, the audience and its surrounding, the subject, and the content. This paper will also discuss what is behind digital painting which includes some technical issues including concept of digital image, the hardware and the software. This paper will confer some Malaysian digital paintings situation and scenario. Subsequently, it summarizes the core elements in digital painting to be implemented in further studies.
\end{abstract}

Keywords: digital; painting; digital painting; new media in art; new media art.

\section{$1 \quad$ Introduction}

Media in art play a vital role to bring artists' ideas, expressions, messages, interpretations and imaginations. In ancient times, the artists were much close to the chemists, the pharmacists, the psychologists and the priests as well. They used tempera and mosaic, which later on replaced by oil paint and fresco. Starting from a natural medium such as oak and poplar panels and canvas, artists also prepared their painting ground with eggs, rye paste and gesso. Before artists turned to pigments materials on tube, Maria Bazzi [1] found that the earliest painter only knew white, yellow ochre, red ochre and black.

Ranges of colors were expanding when the Egyptians used various colors from minerals and organic sources such as vegetables. Chemical reactions, fading effects, binding the media, damping and mildewing will alter the tones of

Received July $5^{\text {th }}, 2010$, Revised October $29^{\text {th }}, 2013$, Accepted for publication November $8^{\text {th }}, 2013$

Copyright ( 2013 Published by LPPM ITB, ISSN: 1978-3078, DOI: 10.5614/itbj.vad.2013.4.1.8 
colors. From natural media, artist turned to industrial media such as pigments on tube. These materials are known as conventional media. In digital era, artist turned to computer and produce computer works.

In Malaysian context, Muliyadi [2] stressed on the different media to justify what is meant by Malaysian modern art. According to him, artworks that differ from any traditional artistic convention were considered as Modern Malaysian art. From traditional craft making using natural materials, Malaysian artist started to use brush, water color, oils and surfaces such as paper and canvas. Those media were applied by the immigrants during British Colonization in the 19th century. In parallel with digital era, Malaysian artist also explored computer application in their artworks.

\subsection{New Media in Art}

Wilson [3] found that the transition of media application was revolutionizing within art developments. Artist turned to another materials, media, tools and technique to suggest another ideas and expressions in different styles or 'ism'. In the second decade of $20^{\text {th }}$ century, Dadaism artists experiment new artistic practices and idea, showed reaction to the industrialization of warfare, worked on mechanical reproduction of texts and images, respond to information technology and digitization materials [4]. Bahaus and pop artist used industrialized materials, products and processes as art medium. Artist started to use natural setting with residential materials in earth art. In interactive art, artist interacts with its audience and make happening situation in performance art. Walker [5] indicated a Canadian artist named Les Levine who claimed himself a creator of the term media art. Since 1960s, Les Levine worked on diverse range of materials and media, up to mass media and mass communication channels especially video tapes, photographs and billboard. Nowadays, artist explores technological innovation such as video, copier, laser and holography.

Rosyida Mohd Roslan [6] also discovered that earlier Malaysian illustration was created by paint from minerals such as hematite, gypsum and charcoal which were then mixed with binder to produce a powder type of media. Water color painting was applied in Malaysia where Penang water color artist was verified in 1930s. Penang water colorist actively produced landscape painting of Malaysia such as Yong Mun Seng (Cocunut tree, 1951 and Small Hut by the Sea, 1960) and Abdullah Arif (Coconut Plantation). Mohamad Ali Abdul Rahman [7] stressed that before water color painting, oils was applied in Catherine Sim's painting. Chaterine Sim's self portrait using oils was exposed by Zakaria Ali [8] dated in 1949. However, Ahmad Suhaimi Mohd Noor [9] discovered another few names who exploited water color earlier than that such 
as Frank Swettenham and George Giles in painting entitled "Perak River from the Residency Kuala Kangsar" created in 1884.

There was also pastel work such as in Mohd Hoessein Enas's self portrait created in 1958. He also applied charcoal and pastel on paper such as in Woman Pounding Padi in 1959. Gouache was applied in Peter Haris's work entitled "Raft house - Kuala Lipis" in 1956. Besides Western styles and Chinese brushstrokes applied in oil and water colour of Malaysian paintings, there were some influence of Western modern art. Abstract expressionism style was applied in Dance Series by Yusof Ghani in 1989, Cubism style in Sui Ho's work entitled "Bright Day" in 1965 and Surrealism style in Ali Rahman's work [2]. Even though there were various media and approaches imported into Malaysia, some artist remain using local media and technique in their art such as using batik which were found in Chuah Thean Theng's (Fishing Village, 1956), Tay Mo Leong's (Malay Village), Fatimah Chik's (Nusantara Series, 1982), Syed Shaharudin's (Red, Blue and Green fabric, 1982) and Zaliha Shaari's (Mid-West Horizon, 1990) works.

Based on Four Generations Photography Exhibition in 2004 [10], Ibrahim Ismail was the first generation who works on photography and produced digital prints in his work entitled "Landscape" (2002) and "Subuh in Losong" (2004). Besides photo work by Ismail Hashim entitled "I Can Sleep Through Even if The Bomb Explodes", 1984 and "Pemajuan", 1986, photography montage was popularised by Raja Zahabuddin in his Flower of Hope II, (1985), JaffaCola (1987), Greatness of God I (1991), and Greatness of God (2001). Md Yusoff Othman was another photographer who works on digital technology and also the one who produced "Matahari Mengejar Senja, Batu-batu Kehijauan" and Lotus Series using computer manipulation and chemical colour print technique in 2004. He actually started the technique and transferred it on canvas since 1974 in his work entitled "Waiting". Like Dadaism artist, Redza Piyadasa produced his work using found object in 1974 entitled "Towards a Mystical Reality" which brought some political issue regarding the directions of local art at that time.

Mixed media was explored earlier on by artist such as Omar Basaree in Iqra' created in 1969. He used oil paint on glass and gold leaf paper. Mixed-media were obviously explored since 1980s such as in Sulaiman Esa's work named "Nurani" (1983) using handmade paper, yarn, bamboo and acrylic while Mastura Abdul Rahman used oil paint, collage, plywood construction and plant twigs in her Interior No.29. Ruzaika Omar Basaree tried to develop national identity with local motive and wood carving technique in Dungun Series (1981) using emulsion on wooden construction due to depart from western treatment. Local artist continuously explore various media in their paintings and artistic 
works which also challenged their skill and mode of delivery to suggest variety of contents.

\subsection{New Media Art}

The term new media in art is slightly different with the term new media art in a context of its historical period and have some similarity in a context of its concept. It was because new media art or digital art did not arise in art history vacuum $[4,11,12]$. Besides, new media artist comes from multiple skills and disciplines. New media art means new cultural forms, new technology and new twists on political issues [4] such as computer works, multimedia and web art while new media in art is referred as new media used in representing art.

Assortments of new media were applied in art and finally new genre called new media art existed. New media art started its name with various terms such as incorporate digital art, computer art, multimedia art and interactive art. Presently, the word new media art can be defined as art that is in contrary to conventional media typically oil paint, acrylic, and water color and so on. There were few names of fine artist who experiments their works on computer such as Jeniffer Bartlett, Richard Hamilton, David Hockney, and Howard Hodgkin [5]. Pioneer in digital artist David Em created his three dimensional imagery by using computer in mid 1980s and claimed his works as painting [12]. Harold Cohen is another painter who experimented with computer and turned to explore computer programming and produced AARON paintings exhibited around the world. There were also important women painter who explores computer works such as Lilian Schwartz who pioneering computer, film, video, animation and multimedia works.

New media art assembles various disciplines ranging from media and performance, video art, video installation art and the digital in art [13]. Similar to contemporary electronic art, five main trends were raised comprises of laser and holographic art, video art, computer art and communication art [14]. Recently, the word new media art also applied to artworks created using new technologies including computer graphics, computer animations, virtual art, internet art, interactive art, computer robotics, biotechnology art, Ascii art, and artistic computer game modification. To date, Paul [9], combined all new media disciplines and labeled them with the term digital art. The term digital art concurrently applied to film and video, sound art and other hybrid forms. The concept of 'new' in digital art for her is works that offer new possibilities for the creations and new experience of art. She divided digital art into two categories - digital art as a tool (for the creation of digital imaging) and digital art as a medium (to produce, store and present artwork). 
Digital Art museum (DAM) website [15] published the first phase of digital art named as 'The pioneers' (first phase) which started from 1956. For instance, the pioneers of digital artist are Yoshiyuki Abe, Harold Cohen, Charles Csuri, David Em, and Micheal A. Noll. This was then followed by Paint-box Era' (second phase) which started from 1986. It established Steve Bell, Paul Coldwell, Jeremy Garnider and Wolfgang. The latest was called 'The Multimedia Era' (the third phase) which started from 1996. Kerry John Andrews and C.E.B. Reas are the third phase artists.

New media art is much closer to digital art which can easily be understood as works that are produced by computer. Pruitt [16] called it computer aided art because he assumed that artist who uses a computer is considered as using paint brush, hammer and chisel. Rush [13] also combined Christiane Paul's [17] concept of 'tools' and 'medium' as objects to execute an artist's idea.

The word digital art, new media art or computer art illustrates a broad range of disciplines. This discussion will concentrate on painting as one type of those terms. Thus, painting with computer is justified as digital painting by considering classical understanding of painting and open justification to an alternative definition of painting. Because through computers, artist could explore various approach to make an artistic visual images-painting.

New media art in Malaysia can be traced back to the exploration of various technologies and disciplines which later crossed into the era of digital painting. In 1989, Baharuddin Arus performed video art and mobile sculpture in USM (University Science Malaysia) which run through its remote control. Malaysian first Electronic Art Exhibition in 1997 exposed various electronic media used by local artist including light, video and computer works. Light in art was explored by Syed Alwi in his work entitled "Yesterday, Today and Tomorrow". According to Hasnul and Niranjan [18], Kamarudzaman Md Isa was the pioneer in exploring programming in his Self Portrait. Liew Kung Yu, a minor award winner for Young Contemporary used TV monitor displaying figure, text, and cloth wrapping the monitor for his work. Wong Hoy Cheong presented a life performance, painting and video projection in his work entitled "Sook Ching".

Video Art Festival which was held in National Art Gallery in 1994 [19] presented local and international artists who used video as their medium in art. Local artists who took part in the exhibition were Ahmad Kamarul Bahrain (The Making of Animation, 7mins), Faizal Mohd Zulkifli (X'perimental Lightbeat, 3:52 mins), Hasnul Jamal and Noor Azizan Paiman (Bernafas dalam Lumpur, 4:30 mins), Pachingey Lanus (Reflection, 3 mins), Zulkifli Che Haris (A Day in The Life of A Basketball, 5 mins) and few others. The exhibition showed various types of video works including video animation, video experimental, 
and video installation. Noor Azizan Paiman expands local art scene with performance and installation using video. Other names such Khairul Aidil Adlin and Hamzah Tahir produced their video works in Malaysian Video 3M VHQ 94 competition. Video was also applied in local theatres such as in 1989 lead by Normah Nordin from Center Stage, in 1995 during Rama \& Sita and in Ribut directed by Zahim Albakri. The starting point of digital painting in Malaysia should be based on manipulation of computer by local artist.

The most memorable solo exhibition on computer works in Malaysia was by Ismail Zain in 1988 entitled "Digital Collage" which exhibited "Penyanyi Pujaan," "Nasyid," "My Friend Lisa", "The Eye has a Veil" and many more. Later in 1991, Ponirin Amin explored computer and converged the medium into his printmaking work entitled "Al Insyirah". Similar to Ponirin, another print maker named Bahaman Hashim and Suhaimi Tohid produced their silk screen through computer generated image making processes entitled "Virtual Reality" (1993) and "In a Minute" (1994). Those few names still continue their computer works and produce digital painting along with other new names.

\section{Objectives}

This article tries to discuss two major aspects in digital painting which will lead to a comprehensive understanding of the topic. Firstly, it intends to discover digital painting in art perspective. Secondly, it aims to present some technical issue regarding digital painting. Few local digital painting will be included due to promote Malaysian works internationally. Finally all issues discussed will be summarized and concluded with recommendation for further study on digital painting.

\section{$3 \quad$ Methodology}

The discussion of digital painting concept will involve art and painting theories. Justification of digital painting will back to a common concept of painting due to establish it validation. In order to define what art is, someone needs to match the idea with a common belief. It was declared by Collingwood, who said,

"Definition necessarily means defining one thing in terms of something else: therefore, in order to define any given thing, one must have in one's head not only a clear idea of the thing to be defined, but equally. [20]

The technical part will cover some related issues that support digital painting creations. Some explanation on digital will bridge the understanding of painting into digital painting as a whole. 


\section{$4 \quad$ Digital Painting}

\subsection{Conceptual Discussion}

Painting is synonym to art. Literally, Cambridge International Dictionary of English [21] defined art as,

"The making of what is expressive or beautiful, or things that are considered to be expressive or beautiful".

The making means the process or the procedures. Mainly, procedures of art is aim to grow certain impact such good looking, enjoyable or affected any human senses. Aristotle claimed that artist produced artworks as their wish for knowledge such in imitation from nature. Later on, artist started to express various ideas which Plato said that art was produced due to indulge artist desires. Art is always connected to the word beauty. Tolstoy (1828-1910) described beauty as an activity which gives pleasure excitement of human nerves system. Art is also something skillfully constructed by human artist [22]. Therefore, artist is someone who is very good in what they do [20].

The criteria of a person who create art called an artist are important. Vasari (1511-1574) in his texts called The Lives of Artist (1568) showed the importance to identify the background of the artist such his school of thought and his influence of styles. According to him, the quality of art and the perfection of styles are based on artist's mind and skill. In fact, he stated that it is need to understand art through an artist's eye. Instead of artist and art works, audience and its social context are other components which constitute the word art. Therefore, Hauser (1892-1978) believed that it is need to analyze the social context in order to understand art. It was because art was produced by many factors that influenced artist's creation and audience's perception such as education level, class interest and political impacts in the society.

Painting is more than a flat surface covered with paints or colored mark and it should be able to communicate with the audience [23]. Tolstoy (1828-1910) defended that art is a communication of feeling or social enterprise because thorough artwork, artist transfers his information in both emotion and feeling which are concurrent with his belief and based on his past experience.

Painting as an artwork should be understood as a process and a product which can be elaborated in both verb and noun [24]. According to Paul Weiss [24] painting in a context of verb refers to the process of making paint marks on certain surfaces, creative activities done by artists and the process of creating something into being. It requires creative act of painting such new roles, new relationship or meanings. Collingwood (1889-1943) identified art as artist 
imagination which came out from their mind. It is the central point of art creation. Artist controlled the space between himself and his artwork to explain what he really meant in his work. John Dewey (1959-1952) balanced up two spaces in between artist art and audience. He justified art as an experience of artist doing the art form and the experience of audience perceived the art form. Both artist and audience are equally important in order to appreciate art which he called 'aesthetic artistic' process.

In digital painting process, artist such as Charles Scuri produced SineScape who used mathematical function in his work. The activity of sticking or cutting of real or actual texture and simulated texture materials by Picasso, Braque and Robert Rauschenberg was transformed into virtual cut and paste activity. It gives new meanings to the whole textural images and composition of visual art. Digital technology shifts conventional collage into digital collage, montage and compositing which many artists labeled it as juxtaposition, dematerialization and recontextualized process. Ismail Zain in Retrospective Exhibition 19641991 [25] used the word juxtaposition to present his idea on combining the iconic images. He called the procedure as 'Digital Collage'. He said that the derivatives of other unrelated images in painting are considered as foreboder of purpose such as in Malay literature, they are called pantun.

Digital painter manipulates digital tools in virtual mode and handles the tools using physical hardware. Hence, there are two levels of tools in digital painting creation - the tangible hardware and the virtual instruments. Computer as digital tool functioned as sketchpad by Jack Youngerman when he edited the colors and compositions through his screen images. David Em worked on computer application in his computer generated imagery. He produced his digital landscapes through topographical illustration and considered it as painting. Mumtaz Mokhtar used Wacom tablet Intuos 3 to produce her Batik Series in Ilham Exhibition 09 [26]. Even though she worked with virtual brush tool in Illustrator and graphic tablet at the same time, she did not rely on that tool as a whole because it depends on her justification in every movement she took.

Ismail Zain also claimed that it is a human who puts the input on the computer works. Malaysian artist employed digital world as a tool in their works through numerous stances. As reported by Hasnul and Niranjan [18], Ismail Zain used digital tool to replace sketch book normally exercised by conventional artist. They added, Niranjan explored digital media to produce installation drawing as an idealistic form and Hasnul produced his computer prints to argue between hand and digital works [18]. Finally they stated that by using computer, artist rejected their self-centered especially when delivering spiritual concept such as in Nasir Baharuddin's work. 
In a context of noun, painting is considered as an outcome. It is also a product of creative activities and object made by artist [24]. Beardsley (1915-1985) mentioned about art as aesthetic production. He defined art work as art production which includes various artistic activities of physical action such as making, altering, assembling and joining. The art production also needs audience intention which he called as reception. In Ilham 09 art exhibition [26], Mumtaz Mokhtar printed her digital painting on canvas in order to produce a tangible form which can be perceived by audience permanently even though she found that her digital painting is a 'reptile' work - can exist in both softcopy and hardcopy format. Printed digital works on canvas made documentation and preservation of artworks easier such as Ponirin Amin and Rahman Amin's work which was collected by Johor Art Gallery.

Digital painting was also considered as painting product in a flexible perspective. Christiane Paul [17] declared computer work as an artistic medium. Digital artist employed digital medium as a platform from production to presentation. In a context of medium, the aesthetics of form take place through various modes including interactive, participatory, dynamic and customizable. Thus Davis in his essay The Work of Art in the Age of Digital Reproduction (An Evolving Thesis: 1991-1995) studied the potential of reproduction of art. He claimed that the dichotomy between original and the reproduction has its own aura. For him, the reproduction which he called post-original original will not limit the creativity potential of artist.

Artists work on a specific theme or subject in their painting in order to work on some details and concentrate on a particular imagery. Subject in painting is like a problem to be solved. Daniel Wade and Mark Snoswell [27] sorted out twelve categories for digital painting themes. It was labeled as Character in Repose, Character in Action, Portraits, Transport, Wildlife, Environment, Still Life, Abstract and Surreal, Humorous, Editorial Illustration, Fantasy and Concept Art. In digital still life paintings, Micheal Collery, Harold Hadelman, Alan Bar, David Weimer and Tuner produced efficient transparency, reflection, and textures in their still lives painting in 1980s. W Robert Chang set his own setting and life model for his portrait painting in Digital Painting book (2006).

It is important to understand the form in digital painting. Clive Bell (1881-1964) mentioned about art as a significant form who justifies the art through the formalistic arrangement such as lines and colors. Digital artist employed the same formalistic or visual language like other traditional painter. In fact they enhanced it. They used elements and principles of art while managing their subjects. Gaunt [28] stated that color is a statement of form. Knowledge on colors is vital in digital painting hence, artist emphasized on color rendering to 
create visual form. Some treat their painting as pixels on electronic canvas. In digital painting, one bit could represent black or white in the screen.

Gaunt also claimed that mathematics is an idea of form where the circle, straight lines, curves was constructed in Kandinsky and Piet Mondrian compositions [28]. Ruzaika Omar Basare in her Larat Series (2004) explored some mathematical function to create her infinite and intricate composition. She dominantly applied repeated motives in modular form. She flipped the module in vertical and horizontal alignment with various angles to get a proper symmetrical balance of painting. Briefly Ruzaika exploited Islamic pattern arrangement based on Malay wood carving motives to convey an Islamic art philosophy.

In digital painting, artist manages their elements and principles in such different ways. For example, artist manages to organize their vision of space in another dimension where layer allowed them to see the overlapped image and not as hidden image. They could program their color scheme, the hue, the intensity and its luminosity. Realism in digital painting allowed artist to explore real image, real space, and sound and time such in Evans and Sutherland's work entitled F-16's.

As one of vital component in art, the criteria of digital artist or painter play an important role in digital painting. According to Pruiett [16], there were two types of digital artist who were labeled as passive artist and active artist. The passive artist is a person who is less dexterity and less aesthetics spirits. By using computer, they may transform into active artist which enjoyed other types of artistic expressions. He added, digital artist explored more ideas with their fine new tool [16]. Even though computer helps artist to do a job quickly, digital artist still puts an effort in their digital creations as traditional artist does in their creative process such as digital painter master Linda Berkvist, Philip Straub, and Robert Chang. Mike King [29] in Computers in Art Design and Animation mentioned three main reasons why artist uses computer in visual fine arts. Firstly is to increase their productivity, secondly is to explore new types of imagery and finally to be an equal partner in the creative process. Frank Popper [14] agreed that computer art is more than a tool because it functions as purveyor of abstract information.

Basically, the whole scenario of digital painting exists in normal art zone where there are artists who produce the product and perceived by its audiences which was connected through the digital environment. Besides visual appearances, the content of digital painting can be perceived by considering its technical application. 


\subsection{A Technical Discussion}

Cambridge International Dictionary of English [21] determines the word digital as an adjective. It is a communication mode that reads numbers. Elliot and Worsley [30], define digital as storage of information using digit of 0 and 1. In a context of digital graphics, digital can be understood as all information including audio, images, sound and text that will be translated into specific code which a computer could understand. The code is only using series of 0 and 1 to represents different meaning. Winn L. Rosch [31] stated that digital refers to anything which human can perceive such size, weight, length, color or sound that can be measured. Those measured information will then be represented in numerical format.

While working with computer, artists usually use three methods in generating their computer art [32]. First they write their own program due to visualizing the images. Secondly, they write a program to implement a generative concept. Third, they use readymade paint system as the medium in order to make pictures more or less like conventional methods. Besides paint system, there were another new creative media for visual artist such as drafting systems and solid modeling systems [30].

Artist could employ more than one system while creating their digital painting. Briefly, by using various media in various ways through computer or with computer in painting are considered as digital painting. At this time of discovery, Kamarudzaman Md Isa is the only Malaysian artist who explored programming in his image making while others develop more on the paint or design program in their works.

Generally digital painting can be perceived with the same visual literacy in conventional painting. But, it is more important to understand that digital painting has its own story behind it. It is about digital image. Images that are displayed on computer screen or off screen consist of data or information (binary data). In the context of painting, data or information could be line, colors, shape or texts. For example, Vera Molnar produced Parcours in 1976 with combination of repeated straight horizontal, vertical and diagonal lines to suggest minimalist art. Earlier, Micheal A Noll produced Gaussian quadratic in 1963 using straight lines and emerge geometric shapes to suggest cubism art. Data stored in computer memory called bit (single piece of information). For example, a single bit display either white or black screen. Combination of eight bits could represent 256 differences of grey or colors.

Pixel is an image that people perceive on screen or can be understood as the smallest visual unit on the screen. It represents a location of data in computer 
memory. Pixel is characterized as point or a stroke in pointillism painting. Thus, artist could work on his image and zoom in up to a molecule or pixels such in Seurat's painting. Whereas resolution is the fineness of screen display or printed images. Images will look clearer with high resolution which uses more pixels.

Different types of files format indicated different quality of images. There were TIFF (Tagged File Format), EPS (Encapsulated PostScript), JPEG, GIF, PICT, and PDF file format. The formats give different option for various purposes and allow artist to organize a systematic data based on organization. Digital painting can consist of vector or raster image. Vector image can be described as an outline of shape drawn by pencil and it is resolution independent. Whereas raster image is like water color strokes dissolve on paper like a woven fabric where the colour could not be separated or moved independently. Some of Malaysian digital painting were created using vector image such as the ones found in Mumtaz Mokhtar (Batik 1, 2009) and Ruzaika Omar Basaree (Siri Larat, 2004). Some explored more on raster image such as the ones by Ismail Zain (Nasyid, 1988), Ponirin and Rahman Amin (Pengembaraan, 2003), Kamarudzaman Md Isa (Tribute to Bapak, 1987), and Suhaimi Tohid's work (Journey, 2001).

Digital artist employed both computer hardware and software in digital painting. Hardware refers to all input devices, output devices and storage devices [33]. It consists of electronic components along with an information processing system that can be seen and touch. Hardware has its special telecommunication devices so that user can set their input in input devices, process it in storage device and produce it in output devices.

Keyboard, mouse, microphone and PC camera are common input device. Data will be transmitted according to the specific function of the hardware such as key in keyboard that contains alphabet, punctuation and numbers. Artist usually used graphic tablet to draw or design in most free movement and produce convenience strokes. Graphic tablet allows artist to prevent an artificial strokes compared by using mouse [34]. To date there were new technology developed by Chu Siu Hang [35] based on his $\mathrm{PhD}$ research that produced physical based technique to get natural looking marks through brush tool.

A well-known company, Wacom Intuos introduced new technology with intelligent system, the slim and light size, and upgraded resolutions. Artist such as Linda Bergkvist produced her digital painting mainly by using Wacom Intuos A5 tablet. John Wallin a matte painting for Big Fish, Harry Potter and Alien vs. Predator also enjoy using Wacom tablet in his painting. Based on an interview with Katsuya Terada by Wacom website [36] he justified that Intuos3 was the best tool for drawing yet very constructive to become more natural tool. He 
could create original image digitally and got the exact quality like using the real pencil-drawn image.

Malaysian artist named Kamarudzaman Md Isa is an artist who worked on various computer technology including its system, hardware and software beginning in 1983 until 2000s. In 1983 he worked on programming system and turned to DOS prompt until 1987. He later changed his computer system into MS window after 1997. He experienced his digital image making using Apple IIe, Commodore, IBM PC, Commodore Amiga 1000, and finally used PC computer with higher RAM, processor, and higher color display monitor with far better sound quality. Earlier, he only experimented with programming language to produce his self portrait but in 1984 he manipulated Basica and GW basic programming language until 1987 where Duluxe Paint offered him more possibilities in his painting. Since 1997, he finally explored Adobe softwares, Fractal Painter, Micromedia Director as well as 3DSMax.

Shelly, Cashman and Vermaat [37] indicated three most familiar output devices including monitor, printer and speaker. To date, holograph technology allows artist to visualize the painting in more interesting and new dimension of perception. Input devices function to enter data and output devices function to execute data and storage devices function to hold the data. Data recorded in computer memory is called as softcopy. The common issue arises with soft copy files of digital painting is the authority and originality of artwork. This scenario can be controlled by Digital Rights Management (DRM) systems and protecting the Intellectual Property (IP). Monitors and all display devices present visual information while printers produce physical medium of data applicable on paper, transparencies, or any printed medium. Printed information or data is known as hard copy.

There was water marking technology which applicable for artist to prevent their original work or controlled the output of tangible product. Wipro Technologies [38] recommended Least-Significant-Bit (LSB) watermarking for inserting digital watermarking in still image. For hard copy of digital painting, Giclee print offers high quality product using ink jet printers. It was considered as fine art work because the printing is based on demand which is limited in edition [39]. The quality of images painted using Giclee print is identical with its original [40].

In storage devices, data can be hold permanently in the memory and can be processed in temporary memory. Data can also be stored in a storage medium usually in discs. 
Besides hardware, software is another component where artist exploits digital painting. Software is a program. The computer program includes a series of instructions that instruct computer hardware to do the job. The software needs to be installed in the computer hard disc before it can perform or execute the instructions. There are two categories of software named as system software and application software. System software controls the operation of the computer through user interface such as Microsoft windows. Application software consists of programs which run a specific task such as Adobe Illustrator, Adobe Photoshop, CorelDRAW, Macromedia FreeHand, and MetaCreation Painter 3D software for paint or image editing. Painter software by Corel leads the most natural media [34] for digital painting which offers various types of wet and dry medium used by traditional artist including pen, pencil, crayon, chalks and watercolours.

Tehrani [41] in Animation Magazine February 1999 edition, ranked After Effects Adobe as the number one best software for graphics imaging because it is the most widely used for special effects and post production tool for both compositing and 2D animation. The second rank was awarded to Aura Newtek which offers full integrated system for painting. The third best software title was given to Digital Fusion Eyeon. But in 2002 [42], the same Magazine ranked Adobe Photoshop as the first ranking for top 10 inks and paint, 2D Digital Animation and Digital Painting software. The second top ranking was Axa Team 2D and Corel Painter 6.1 was in third place. Corel painter was judged as the best digital fine art package [43].

Nowadays, there are many studies and discussion on aesthetic computing, aesthetic programming and aesthetic cybernetics where computer scientists such as Fishwick, Diehl, Prophet and Lowgren and Korean group Hyunkyoung Chu and Joonsung Yoon distinguish their artistic taste in computer pasture. The story behind digital painting became more exciting when Ben Fry and Casey Reas [44] initiated Processing 1.0 in 2001. The software allows users to design,

draw, animate and design interactive works which also offer an open source of data. This means that the programming or data behind the art work can be 'read' by audience.

\section{Conclusion}

The core concepts of using different media and transmitting one media to another in art movements depend upon media technology available in certain period, and also the desire of artist to explore new concepts. Digital painting contains four major components which categorize them as true art which brings prior concepts of art through history. Digital painting brings catalyst to new aesthetics experiences, new form discovery and new mode of appreciations. 
Even though digital technology arises as a tool or medium in digital painting, it transforms the model of artist, shifts the paradigm of painting process and its product, as well as branding audience standard due to developed system of social acceptance on digital painting as new aesthetics experience. Four components that constitute digital painting are summarized as followed:

1. The artist/painter: Digital painting is created by skilled human artist. They work on cognitive and affective domain while coordinates their psychomotor movements. Beside minds and emotions, they deal with physical and virtual mode of doing.

2. The form: Digital painting remains its visual literacy while adding new ones such as the dimension and the non linear processes. Without the process of doing painting, the product (painting) has difficulties to congeal the level of its representation. Digital painting brings about digital images which contain subject, form, content and data.

3. The audience: Instead of sharing expression, experience and pleasure, audience grasps knowledge and information in digital painting physically or virtually.

4. The Environment: The surrounding where artist and its audience are communicating through digital paintings. The acceptance of digital painting also depends on the role of society such curators, art historians, art critics and its patron. They are affected by various social context including culture, economy, technology, knowledge, and belief.

The exceeding components can be used as guidelines on appreciating or analyzing digital painting. Thus this paper proposes further research on the implementation of the guideline in selected digital painting such in Malaysia. Detailed study on Malaysian digital painting will enlighten more about this topic which requires more finding to be documented for further references. It is also crucial to look at the latest art theories where the digital media yearn for new philosophy of art. This paper also believed that Islamic art theory or philosophy could be relevant to complement other art theories for analyzing digital painting.

\section{References}

[1] Bazzi, M. 1965. The Artist's Methods and Materials, (Translated by Francessca Pruili), London: John Murray (Publishers) Ltd.

[2] Mahamood, M. 2007. Modern Malysian Art; From the Pioneering Era to the Pluralist Era (1930s-1990s), Kuala Lumpur: Utusan Publishing \& Distributors Sdn. Bhd.

[3] Wilson, S. 2002. Information arts; Intersections of Art, Science and Technology, London: The MIT Press, Cambridge, Massachusetts. 
[4] Tribe, M. 2007. Defining New Media Art. Brown Atlassian Confluence, The Enterprise Wiki, Retrieved April 24, 2009, from https://wiki.brown. edu/confluence/display/MarkTribe/New+Media+Art+-+Introduction.

[5] Walker, J.A. 2001. Art in the Age of Mass Media, $3^{\text {rd }}$ Ed., London: Pluto Press.

[6] Rozlan, R.M. 2008. The Growth and Development of Illustration in Malaya: An Overview from the Material and Technical Aspect, Timelines, Malaysia: National Art Gallery, pp. 124-136.

[7] Rahman, M.A.A.. 2004. Modern Malaysian Art: Manifestation of Malay Form and Content, Shahh Alam: Biroteks University Teknologi MARA.

[8] Ali, Z. 2008. Jelita Malaya Malayan Beauty, Timelines, Malaysia: National Art Gallery, pp. 152-159.

[9] Noor, A.S.M.. 2008. Illustrated News of Malaya, Timelines, Malaysia: National Art Gallery, pp. 110-1117.

[10] Zain, D.H.M. (Guest Curator). 2004. 4 Generations Photography Exhibition, Shah Alam: Shah Alam Gallery.

[11] Paul, C. 2008. Digital Art (Revised and Expanded Edition), New York: Thames and Hudson

[12] Arnston, A.E. 2006. Digital Design Basics, Australia: Thomson Wadsworth.

[13] Rush, M. 2005. New Media in Art (New Edition), London: Thames and Hudson.

[14] Popper, F. 1993. Art of the Electronic Age, London: Thames and Hudson.

[15] Digital Art Museum (DAM). 2007. Artist, Sponsored by hauntPharma, Retrieved April 24, 2009 from http://dam.org/sponsor.htm.

[16] Prueitt, M.L. 1984. Art and the Computer, New York: McGraw Hill Book, Company.

[17] Paul, C. 2003. Digital Art. New York: Thames and Hudson.

[18] Saidon, Hasnul Jamal \& Rajah, Niranjan (Guest Curators). 1994. First Electronic Art Exhibition, Malaysia: National Art Gallery.

[19] Video Art Festival Catalogue. 1994. Malaysia: National Art Gallery.

[20] Waternberg, T.E. 2007. The Nature of Art an Anthology, $2^{\text {nd }}$ Edition, Australia: Thomas Wadsworth.

[21] Cambridge International Dictionary of English. 1995. London: Cambridge University Press.

[22] Goguen, J.A. 2000. What is Art? Editorial Introduction to Art and the Brain, Part 2, Journal of Consciousness Studies 7(8/9), Aug/Sept 2000, pp.7-15.

[23] Simpson, I. (ed.). 2001. The Complete Painting Course, London: Greenwich Editions.

[24] Weiss, P. 1961. Nine Basic Arts, Carbondale: Southern University Illonois Press. 
[25] Piyadasa, R. (Guest Curator). 1995. Ismail Zain: Retrospective Exhibition 1964-1991, Kuala Lumpur: National Art Gallery.

[26] Ilham '09 (Exhibition Catalogue). 2009. Faculty of Art and Design, Shah Alam: Universii Teknologi MARA.

[27] Wade, D. \& Snowswell, M. (eds.). 2006. Digital Painting, Australia: Ballistic Publishing.

[28] Gaunt, W. 1967. A Companion to Painting, London: Thames and Hudson.

[29] King, M. 1989. Towards in Integrated Computer Art System, Computers in Art Design and Animation, New York: Springlet Verlag.

[30] Elliot, J. \& Worsley, T. 1996. Mulimedia the Complete Guide, London: E'lan Press.

[31] Rosch, W.L. 1995. Multimedia Bible. Indianapolis: Sams Publishing.

[32] Lansdown, J. \& Earnshaw, R.A. 1989. Computers in Art, Design and Animation, New York: Springer-Verlag.

[33] Sesonke, A. 1965. What is Art? Aesthetic Theory from Plato to Tolstoy, in Fuller, F. \& Manning, W. 1994. Computer and Information Processing. Massachusettes: Boyd \& Fraser.

[34] Caplin, S. \& Banks, A. 2003. The Complete Guide to Digital Illustration. New York: Watson-Guptil Publication.

[35] Chu, S.H. 2007. Making Digital Painting Organic, PhD Thesis, Hong Kong University of Science and Technology.

[36] Wacom website, Illustrator Katsuya Terada, http://www.wacom.com.au/ intuos3/professional/creator 01.html (10 November 2008).

[37] Shelly, Cashman, Vermaat \& Walker. 2000. Discovering Computers 2001, Concepts for a Connected World, Australia: Course Technology.

[38] WIPRO Technologies, Digital Watermarking: A Technology Overview, White Paper, http:///www. wipro.com (13 November 2008).

[39] Franklin, T., Feeling Fine; Giclee Printers Enjoy Benefits of Fine Art Reproduction, Digital Output 2007, http://www.digitaloutput.net/content/ ContentCT.asp?P=848 (27 August 2007).

[40] Magregor, D., What is Giclee Print?, About.com, http://painting.about. com/cs/printing/a/gicleeprints_2.htm (27 August 2007).

[41] Tehrani, B. 1999. The Big 13s of Computer Graphics Imaging, Animation Magazine Feb. 1999, 13(2), pp. 63.

[42] Animation Magazine. 2002. Top 10 Ink-and-Paint, 2D Digital Animation and Digital Painting Software, Jan. 2002, 16(1), p.64.

[43] Business Wire, Inc. 2007. Introducing Corel ${ }^{\circledR}$ Painter TM X Curriculum; Free Courseware Makes it Easy to Intergrate Digital Art into the Classroom, February 7, 2007, Lexis-Nexis.

[44] Fry, B. \& Reas, B. 2009. Processing 1.0 website, Hosted by Media Temple, from http://processing.org/ (29 April 2009). 